\title{
Effect of Amlodipine Alone and in Combination with Enalapril on Lipid Profile in Hypertensive Patients with Chronic Kidney Disease (Gaza Strip)
}

\author{
Hidaya Sobhi Saker ${ }^{1, *}$, Amin Tawfeeq Hamed ${ }^{2}$, Amal Fares Jamee ${ }^{3}$, Mahmoud Jalal Wadi ${ }^{4}$ \\ ${ }^{1}$ General Administration of Pharmacy, Ministry of Health, Gaza, Palestine \\ ${ }^{2}$ Collage of pharmacy, Alazhar University, Gaza, Palestine \\ ${ }^{3}$ Al Shifa Hospital, Cardiology Department, Ministry of Health, Gaza, Palestine. \\ ${ }^{4}$ Nasser Medical Complex, Kidney and Dialysis Department, Ministry of Health, Gaza, Palestine
}

Email address:

hidaya78@gmail.com (H. S. Saker)

*Corresponding author

\section{To cite this article:}

Hidaya Sobhi Saker, Amin Tawfeeq Hamed, Amal Fares Jamee, Mahmoud Jalal Wadi. Effect of Amlodipine Alone and in Combination with Enalapril on Lipid Profile in Hypertensive Patients with Chronic Kidney Disease (Gaza Strip). American Journal of Clinical and Experimental Medicine. Vol. 4, No.5x, 2016, pp. 146-150. doi: 10.11648/j.ajcem.20160405.16

Received: August 23, 2016; Accepted: September 3, 2016; Published: October 11, 2016

\begin{abstract}
Hypertension with dyslipidemia is becoming a common morbidity and hyperlipidemia is considered as an independent risk factor in development of cardiovascular diseases [1]. To evaluate the effects of Amlodipine (Calcium channel blocker) alone and in combination with Enalapril (Angiotensin Converting Enzyme inhibitor) on serum lipid profile in hypertensive patients with Chronic Kidney Disease (CKD), fifty hypertensive patients with CKD were divided equally into Amlodipine $(5-10 \mathrm{mg} /$ day) treated group and Amlodipine/Enalapril combination $(5-10 \mathrm{mg} /$ day, $10-20 \mathrm{mg} /$ day) treated group. Serum lipid profile were determined before and after 2, 4 and 6 months of treatment in both groups. A significant decrease in the levels of serum lipid profile in the hypertensive patients with CKD resulted with Amlodipine therapy alone and in combination with Enalapril. In both treated groups, the used drugs significantly improved Total cholesterol (TC), Triglycerides (TG), High Density Lipoprotein Cholesterol (HDL-C) and Low Density Lipoprotein Cholesterol (LDL-C) levels of the patients. The effect on these parameters being more pronounced in the group treated with the combination drug, when compared to that of Amlodipine treatment alone. The results indicated that both, Amlodipine monotherapy as well as Amlodipine/Enalapril combination affect the lipid profile. The observed overall higher protective effect of the combination as compared to that of Amlodipine monotherapy may improve the cardiovascular changes caused by hypertensive nephropathy.
\end{abstract}

Keywords: Chronic Kidney Disease, Serum Lipid Profile, Hypertension, Amlodipine, Amlodipine/Enalapril Combination

\section{Introduction}

Many clinical studies have clearly indicated that hypercholesterolemia and hypertension are the most important risk factors for cardiovascular and coronary artery diseases [2]. One of the most co-morbidities associated with hypertension, diabetes mellitus, and end-stage renal disease is arterial stiffness, which increases with age. It is also considered a marker for cardiovascular risk factors and organ damage [3]. Little is known about the role of hypertension in the atherothrombotic process, where dysfunction of endothelium-dependent regulatory systems may play a role in cardiovascular diseases, such as hypertension and atherosclerosis [4].

In addition, hypertension could stimulate the proliferation of smooth muscle cells or induce the rupture of the plaque. The presence of a lesion in the target organs (left ventricular hypertrophy and/or microalbuminuria) is accompanied by an increase in cardiovascular risk. A number of clinical trials have demonstrated that a decrease in arterial blood pressure is associated with significant reductions in the rate of stroke, and to a lesser extent, in that of coronary events and circumstances that produce an overall decrease in 
cardiovascular mortality [5]. Hypertension is a major risk factor for arteriosclerosis and the beneficial effects of lowering blood pressure on the vascular morbidity and mortality are well documented and demonstrated [6].

The relationship between serum cholesterol levels and the incidence of heart diseases has been demonstrated in experimental and epidemiological studies, which is continuous, gradual and highly intense. The risk attributed to hypercholesterolemia is due to LDL-C. Many clinical studies have demonstrated that lowering LDL-C levels by means of hypolipidemic agents is accompanied by significant reductions in cardiovascular morbidity and mortality. An independent, inverse correlation between HDL-C and the risk of heart diseases has been observed in several studies. The protection provided by HDL-C is independent of the LDL-C concentration. The National Cholesterol Education Program (NCEP) considers the HDL-C level below $40 \mathrm{mg} / \mathrm{dl}$ to be a risk factor, whereas concentrations over $60 \mathrm{mg} / \mathrm{dl}$ are reported to be a negative risk factor [7]. The calcium-channel blockers (CCBs) and the angiotensin converting enzyme inhibitors (ACEIs) are among the preferred antihypertensive drugs for the treatment of arterial hypertension in patients with coronary artery disease (CAD), because they protect the target-organs with low incidence of adverse reactions [8].

\section{Materials and Methods}

\subsection{Study Design}

This study was a non-randomized, prospectivecomparative study in which the effect of Calcium Channel Blocker, Amlodipine monotherapy and in combination with Angiotensin Converting Enzyme Inhibitor, Enalapril on lipid profile was evaluated in hypertensive patients with renal dysfunction over 6 months. All patients were asked to sign a written informed consent to the ethics committee approved study and guidelines of good clinical practice was given to them.

\section{Study Setting and Period}

The study was performed on hypertensive patients with renal diseases at Nasser Medical Complex, Gaza Strip. The period of the study was 6 months. Lipid profile (TC, TG, LDL-C and HDL-C), serum creatinine ( $\mathrm{SCr}$ ) and creatinine clearance $(\mathrm{CrCl})$ were measured at zero time before starting the study and then every 2 months.

\subsection{Patients}

\subsubsection{Study Population}

All cases participated in this study were hypertensive patients (blood pressure more than 140/90) from both genders with serum creatinine level $\geq 1.2 \mathrm{mg} / \mathrm{dl}$, creatinine clearance $\geq 30 \mathrm{ml} / \mathrm{min} / 1.73 \mathrm{~m}^{2}$ and Urinary Albumin Excretion Rate (UAE rate) $\geq 30 \mathrm{mg} /$ day.

\subsubsection{Exclusion Criteria}

Patients who had DM, cancer or any life-threatening disease, end-stage renal disease or dialysis, secondary hypertension or heart failure; Patients who were previously treated with CCBs and ACEIs; or have hypersensitivity to CCBs and ACEIs. Patients with contraindication to ACEIs like renal artery stenosis and if creatinine clearance decreased or increased more than $20 \%$ during the treatment course.

\subsection{Methods}

One hundred outpatients with essential hypertension attending Nasser Medical Complex, Kidney and Dialysis Department, were selected to participate in this study. The criteria for eligibility included age over 40 years, from both sexes. All cases $(n=50)$ were hypertensive $(B P \geq 140 / 90$ $\mathrm{mmHg}$ ) with impaired renal function (CKD stages I, II and III), which was determined by the $\mathrm{CrCl} \geq 30 \mathrm{ml} / \mathrm{min} / 1.73 \mathrm{~m}^{2}$, serum creatinine $\geq 1.2 \mathrm{mg} / \mathrm{dl}$ and $\mathrm{UAE}$ rate $\geq 30 \mathrm{mg} /$ day. All patients were on their usual diet and no dietary advice was given to them. Patients were divided into the following groups according to specific treatment regimen as follows:

- Group I: Twenty-five (25) hypertensive patients with CKD, They were treated with 5-10 mg Amlodipine tablet, once daily for six months.

- Group II: Twenty-five (25) hypertensive patients with CKD, They were treated with a combination of 5-10 mg Amlodipine and 10-20 mg Enalapril tablets once daily for six months.

For all patients, serum levels of Cholesterol, Triglycerides, LDL-C, HDL-C, were measured before starting the study and then every 2 months of treatment for 6 months.

To test the differences between groups, paired student's ttest was used. Differences were considered significant at $\mathrm{P}<0.05$.

\section{Results}

Table 1 shows the Vital signs and laboratory characteristics of study population at the beginning of the study, where all patients were suffering from hypertensive nephropathy. Table 2 shows the effect of Amlodipine treatment on lipid profile among the study population. For more illustration, total cholesterol level was $227.32 \pm 56.33 \mathrm{mg} / \mathrm{dl}$ before treatment with Amlodipine $(5-10 \mathrm{mg} /$ day) and significantly decreased $(p<0.05)$ to $187.84 \pm 46.84 \mathrm{mg} / \mathrm{dl}$ at the end of the sixth month. On the other hand, triglycerides was $244.84 \pm 137.55$ $\mathrm{mg} / \mathrm{dl}$ at baseline, then decreased significantly $(p<0.05)$ to $199.12 \pm 81.11 \mathrm{mg} / \mathrm{dl}$ and $177.8 \pm 75.34 \mathrm{mg} / \mathrm{dl}$ after 4 and 6 months of treatment. Moreover, HDL-C significantly increased $(p<0.05)$ from $39.76 \pm 9.49 \mathrm{mg} / \mathrm{dl}$ before treatment with Amlodipine to $46.64 \pm 7.25 \mathrm{mg} / \mathrm{dl}$ after 6 months of treatment. While LDL-C significantly decreased $(p<0.05)$ from $138.59 \pm 61.06 \mathrm{mg} / \mathrm{dl}$ at baseline to $105.64 \pm 47.38 \mathrm{mg} / \mathrm{dl}$ at the end of the sixth month treatment with Amlodipine.

Table 3 shows the effect of Amlodipine/Enalapril combination treatment on lipid profile among the study population during the study period. To clarify, total cholesterol was $236.92 \pm 47.88 \mathrm{mg} / \mathrm{dl}$ before treatment with Amlodipine/Enalapril combination and significantly decreased $(p<0.05)$ to $179.80 \pm 30.54 \mathrm{mg} / \mathrm{dl}$ at the end of the 
study. Moreover, triglycerides was 298.72 $\pm 254.97 \mathrm{mg} / \mathrm{dl}$ before starting the study and significantly decreased $(p<0.05)$ to $212.92 \pm 138.32 \mathrm{mg} / \mathrm{dl}$ at the end of treatment course. On the other hand, HDL-C significantly increased $(p<0.05)$ from $39.40 \pm 6.91 \mathrm{mg} / \mathrm{dl}$ before treatment with
Amlodipine/Enalapril to $45.32 \pm 4.75 \mathrm{mg} / \mathrm{dl}$ after 6 months of treatment. While LDL-C significantly decreased $(p<0.05)$ from $137.78 \pm 48.22 \mathrm{mg} / \mathrm{dL}$ at baseline to $92.29 \pm 29.66 \mathrm{mg} / \mathrm{dl}$ after 6 months of treatment.

Table 1. Vital signs and laboratory characteristic of study population.

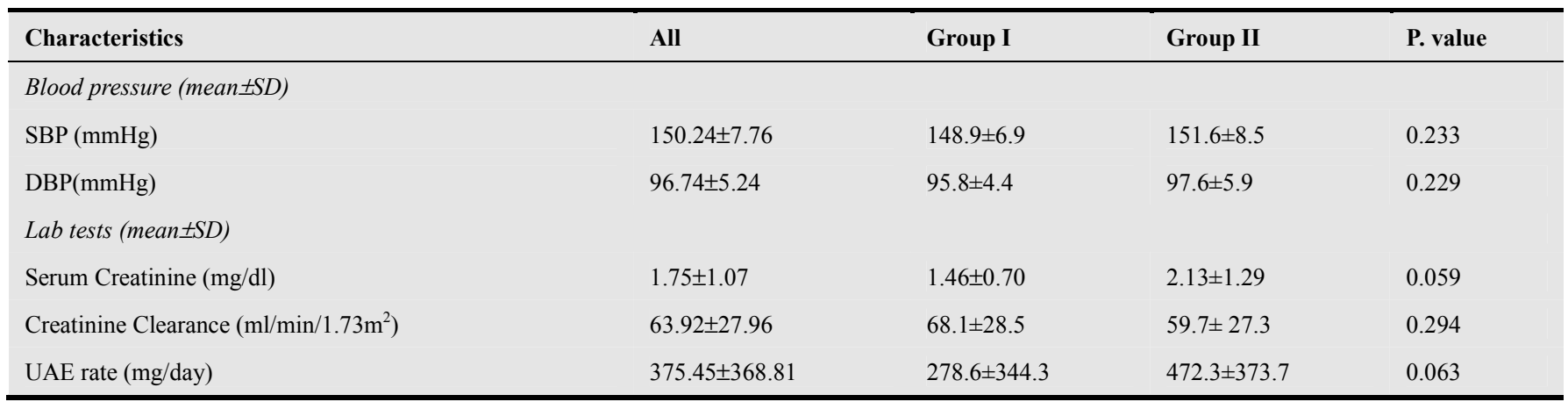

$\mathrm{SBP}=$ Systolic Blood Pressure, $\mathrm{DBP}=$ Diastolic Blood Pressure, UAE rate $=$ Urinary Albumin Excretion rate, $\mathrm{SD}=\mathrm{Standard} \mathrm{Deviation}$

Table 2. Lipid profile changes in group I over 6 months of treatment.

\begin{tabular}{|c|c|c|c|c|}
\hline Parameter & Zero time & After 2 months & After 4 months & After 6 months \\
\hline $\mathrm{TC}(\mathrm{mg} / \mathrm{dl}) \mathrm{Mean} \pm \mathrm{SD}$ & $227.32 \pm 56.33$ & $207.44 \pm 53.11$ & $199.84 \pm 51.61$ & $187.84 \pm 46.84$ \\
\hline$\%$ Decrease & & 8.75 & 12.09 & 17.36 \\
\hline HDL-C (mg/dl) Mean \pm SD & $39.76 \pm 9.49$ & $43.28 \pm 8.96$ & $44.36 \pm 8.21$ & $46.64 \pm 7.25$ \\
\hline$\%$ Increase & & 8.85 & 11.56 & 17.30 \\
\hline$\%$ Decrease & & 18.38 & 16.54 & 23.77 \\
\hline TG (mg/dl) Mean \pm SD & $244.84 \pm 137.55$ & $219.79 \pm 106.81$ & $199.12 \pm 81.11$ & $177.8 \pm 75.34$ \\
\hline$\%$ Decrease & & 10.23 & 18.67 & 27.38 \\
\hline
\end{tabular}

Table 3. Lipid profile changes in group II over 6 months of treatment.

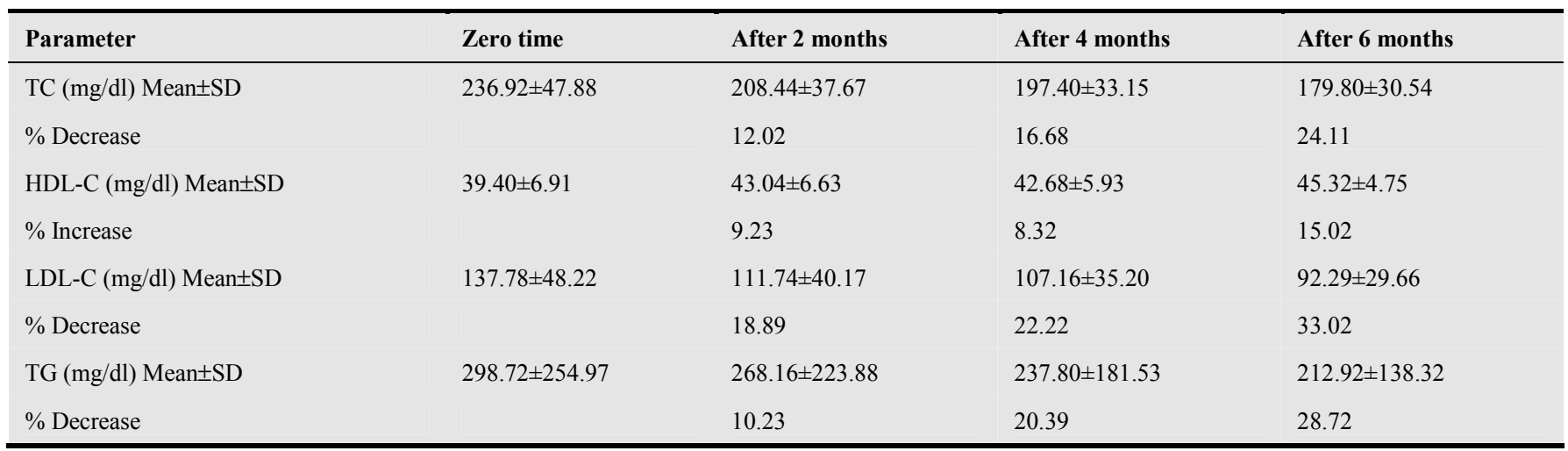

The results presented in table 4 compared the differences between the changes in lipid profile levels among patients treated with Amlodipine (5-20 mg/day) alone or in combination with Enalapril (10-20mg $\mathrm{mg} /$ day). The results showed no statistical significance differences $(p>0.05)$ between serum total cholesterol and triglycerides levels in both groups throughout the study period. Drugs used showed a beneficial reduction in total cholesterol and triglycerides levels during the study period, but this effect was more noticed in the combination therapy group.

The differences between the changes in LDL-C and HDL$\mathrm{C}$ levels in the Amlodipine treated group and Amlodipine/Enalapril treated group were insignificant $(p>0.05)$ during the study period. This indicates that the drugs used improved serum LDL-C and HDL-C levels in both groups, but the effect on LDL-C was higher in the combination treated group and the effect on HDL-C was more pronounced in Amlodipine treated group (Table 4). 
Table 4. Comparison between Amlodipine and Amlodipine/Enalapril treated groups at baseline and at the end of the study period on tested parameters.

\begin{tabular}{|c|c|c|c|c|c|c|}
\hline Variable & Time & Group I & $\% \Delta$ & Group II & $\% \Delta$ & P. value* \\
\hline TC (md/dl) & $\begin{array}{l}\text { Baseline } \\
\text { After } 6 \text { months }\end{array}$ & $\begin{array}{l}227.32 \pm 56.33 \\
187.84 \pm 46.84\end{array}$ & $\downarrow 17.36$ & $\begin{array}{l}236.92 \pm 47.88 \\
179.80 \pm 30.54\end{array}$ & $\downarrow 24.10$ & 0.111 \\
\hline HDL-C (md/dl) & $\begin{array}{l}\text { Baseline } \\
\text { After } 6 \text { months }\end{array}$ & $\begin{array}{l}39.76 \pm 9.49 \\
46.64 \pm 7.25\end{array}$ & $\uparrow 17.30$ & $\begin{array}{l}39.40 \pm 6.91 \\
45.32 \pm 4.75\end{array}$ & $\uparrow 15.02$ & 0.850 \\
\hline LDL-C(md/dl) & $\begin{array}{l}\text { Baseline } \\
\text { After } 6 \text { months }\end{array}$ & $\begin{array}{l}138.59 \pm 61.06 \\
105.64 \pm 47.38\end{array}$ & $\downarrow 23.77$ & $\begin{array}{l}137.78 \pm 48.22 \\
92.29 \pm 29.66\end{array}$ & $\downarrow 33.01$ & 0.775 \\
\hline $\mathrm{TG}(\mathrm{md} / \mathrm{dl})$ & $\begin{array}{l}\text { Baseline } \\
\text { After } 6 \text { months }\end{array}$ & $\begin{array}{l}244.84 \pm 137.55 \\
177.80 \pm 75.34\end{array}$ & $\downarrow 27.38$ & $\begin{array}{l}298.72 \pm 254.97 \\
212.92 \pm 138.32\end{array}$ & $\downarrow 28.72$ & 0.727 \\
\hline
\end{tabular}

*P. values $(\mathrm{P}<0.05)$ were calculated for $\% \Delta$ by independent-samples t-test.

\section{Discussion}

From this study, we observed that Amlodipine in combination with Enalapril caused higher reduction effect on serum lipid profile. For example, the levels of TC $(24.10 \%)$, TG $(28.72 \%)$ and LDL-C (33.01\%) in hypertensive patients with $\mathrm{CKD}$ decreased more than with Amlodipine alone (17.36\%, 27.38\% and $23.77 \%$ respectively) and increasing HDL-C levels nearly to the same extend as Amlodipine monotherapy $(15.02 \%$ vs. $17.30 \%)$, after 6 months of treatment. This effect of CCBs on serum lipids could be related to the fact that oxidized lipid and calcium regulatory abnormalities appear to play important roles in early atherogenesis secondary to cholesterol enrichment of the cell membrane in endothelial and arterial smooth muscle cells (SMCs) [9].

Moreover, Amlodipine as CCB has membrane-modifying and antioxidant actions at the cell membrane level in addition to its classical calcium channel blocking properties. These multiple pharmacologic actions may explain the cellular mechanisms of the atheroprotective effects of Amlodipine in spontaneous atherogenesis and in accelerated atherosclerotic syndromes. Amlodipine also inhibits the cholesterol-induced increase in calcium permeability in SMCs and has been shown to repair abnormalities in SMC membrane structure. Recent data have also demonstrated that Amlodipine has a marked antioxidant action in membrane bilayers enriched with polyunsaturated fatty acids [10].

The atherogenic serum lipid profile is an important factor in the development of atherosclerosis. Studies on lipid and lipoprotein atherogenic side effect profiles of Amlodipine and other CCBs have been documented, and some of the results from these previous reports are controversial. Some researchers showed that Amlodipine or Nifedipine had either a beneficial or no effect on lipid and lipoprotein levels [11].

Angiotensin Converting Enzyme Inhibitors (ACEIs) impair the production of angiotensin II by inhibiting the enzyme ACE, which converts angiotensin I to angiotensin II [12]. By inhibiting this enzyme, ACEIs also prevent degradation of the vasodilatory and cardioprotective peptide bradykinin [13]. Bradykinin stimulates the release of other important vasodilators like nitric oxide; prostacyclin and endothelium derived hyperpolarizing factor, providing cardioprotective benefits and endothelial protection against remodeling, atherosclerosis and thrombosis [14].

Divergent results obtained by many researchers who studied the effect of different CCB and ACEI agents on lipid profile in hypertensive patients [7, 11, 15-19]. The results of the present study are somewhat similar to that obtained by [15] and [7]. For example, [15] obtained similar results on lipid profile in hypertensive patients by Enalapril and Amlodipine. After one month of treatment, both drugs significantly improved HDL-C and LDL-C levels of the patients; the effect on HDL-C being more pronounced. The overall effect of Enalapril was greater when compared to that of Amlodipine. The results showed that HDL-C increased after 30 days of treatment with Amlodipine and Enalapril. On the other hand, LDL-C, Total Cholesterol and Triglycerides decreased after treatment with Amlodipine. While these parameters decreased after one month of treatment with Enalapril. The study indicated that both, Enalapril as well as Amlodipine altered the atherogenic lipid profile. Another clinical trial done by [7] showed that treatment with $5 \mathrm{mg}$ Amlodipine tablet significantly increased serum level of HDL-C, while there was no significant difference concerning LDL-C compared to their levels before starting the treatment. On the other hand, treatment with Amlodipine/Lisinopril combination provided a significantly greater increase in serum level of HDL-C, without any changes on the level of LDL-C. Insignificant decrease were found in TC, TG and LDL-C levels and insignificant increase in HDL-C level after 24 weeks of treatment with Enalapril as demonstrated by [18] in overweight or obese patients with hypertension. There is some evidence that Amlodipine does not alter serum lipid profile as observed by [19]. They observed that there were no significant changes $(p>0.05)$ in the mean values of HDL-C, TC, LDL-C and TG levels in hypertensive patients after 6 months of treatment with Amlodipine.

It has been reported that many hypertensive drugs are known to alter total cholesterol, TGs and lipoprotein fractions. This may even override the benefits of blood pressure reduction. Amlodipine doubles the activity of smooth muscle cell lysosomal cholesterol ester hydrolase. Smooth muscle cells enriched in lipid contents showed a significant decrease in both free and ester cholesterol. This perhaps might be the mechanism of action by which there is reduction of serum cholesterol levels in patients treated with Amlodipine. Similarly, Amlodipine directly activates the hormone sensitive TGs lipase which is present in abundance 
in fat cells, to cause rapid breakdown of TGs and mobilization of free fatty acids therapy leading to a fall in levels of serum TGs [20].

\section{Conclusion}

In both treated groups, there was a significant reduction in serum total cholesterol, LDL-C and TG levels, after 6 months of treatment. Moreover, the results pointed to a clear and significant increase in serum HDL-C levels at the end of the study period in both treated group. This could lead to a reduction in the formation of cardiovascular atherosclerotic plaques.

\section{References}

[1] S. Chandra, S. P. Singh, I. P. Jain, S. Sigh and V. Kushwaha, "Study of Alteration in Serum Lipids by Enalapril and Ramipril in Albino Rabbits", International Journal of Research in Pharmacology and Pharmacotherapeutics, 3 (1), pp 7-13, 2014.

[2] H. Khan, G. Murtaza, N. Akhtar, S. Khan, S. Azhar, B. Khan, F. Rasool and I. Hussain, "Comparison of the Effect of Calcium Channel Blockers and Non-selective Beta-Blockers on Blood Lipids in Hypertensive Patients", Lat. Am. J. Pharm. 32 (6), pp 940-943, 2013.

[3] R. Imanishi, S. Seto, G. Toda, et al. "High brachial-ankle pulse wave velocity is an independent predictor of the presence of coronary artery disease in men", Hypertens Res, 27, pp 71-78, 2004.

[4] P. Rajendran, T. Rengarajan, J. Thangavel, Y. Nishigaki, D. Sakthisekaran, G. Sethi, I. Nishigaki, "The Vascular Endothelium and Human Diseases", International Journal of Biological Sciences, 9(10), 1057-1069, 2013.

[5] B. Neal, S. MacMahon and N. Chapman, "Effects of ACE inhibitors, calcium antagonists, and other blood pressurelowering drugs: results of prospectively designed overviews of randomized trials. Blood Pressure Lowering Treatment Trialists' Collaboration", Lancet, 356, pp 1955-1964, 2000.

[6] M. Kurata, T. Okura, S. Watanabe, J. Irita, D. Enomoto, M. Johtoku, K. Miyoshi, M. Koresawa, T. Fukuoka and J. Higaki, "Effects of Amlodipine and Candesartan on Arterial Stiffness Estimated by Cardia-Ankle Vascular Index in Patients with Essential Hypertension: A 24-Week Study", Current Therapeutic Research, 69 (5), pp 412-422, 2008.

[7] F. Alhamdani, "Possible beneficial effects of Amlodipine, Lisinopril, and their Combination on lipid profile in hypertensive patients", Iraqi Journal of Veterinary Medicine, 33(2), pp 126-137, 2009.

[8] N. Poulter, H. Wedel, B. Dahlöf, P. Sever, D. Beevers, M. Caulfield et al., "ASCOT Investigators. Prevention of cardiovascular events with an antihypertensive regimen of amlodipine adding perindopril as required versus atenolol adding bendroflumethiazide as required, in the AngloScandinavian Cardiac Outcomes Trial-Blood Pressure
Lowering Arm (ASCOT-BPLA): a multicenter randomised controlled trial", Lancet, 366, pp 895-906, 2005.

[9] R. P. Byington, C.D. Furberg, D. B. Hunninghake et al., "Effect of Amlodipine on the progression of atherosclerosis and the occurrence of clinical events. Prevent Investigators", Circulation, 102, pp 503-510, 2000.

[10] R. H. Hernandez, M. J. Armas-Hernandez, M. Velasco et al., "Calcium antagonists and atherosclerosis protection in hypertension", American Journal of Therapeutics, 10(6), pp 409-414, 2003.

[11] J. E. Ahaneku, K. Sakata, T. Urano et al., "Lipids, Lipoproteins and Fibrinolytic Parameters during Amlodipine Treatment of Hypertension", Journal of Health Science, 46(6), pp 455-458, 2000.

[12] V. j. Dzau, K. Bernstein, D. Celermajer et al., "The relevance of tissue angiotensin-converting enzyme: manifestations in mechanistic and endpoint data", American Journal of Cardiology, 88(9), pp 1L-20L, 2001.

[13] C. Ceconi, G. Francolini, A. Olivares et al., "Angiotensinconverting enzyme (ACE) inhibitors have different selectivity for bradykinin binding sites of human somatic ACE", European Journal of Pharmacology, 577, pp 1-6, 2007.

[14] T. Morishita, M. Tsutsui, H. Shimokawa et al., "Long-term treatment with perindopril ameliorates dobutamine-induced myocardial ischemia in patients with coronary artery disease", Japanese Journal of Pharmacology, 88(1), pp 100-107, 2002.

[15] S. Dharwadkar and T.V. Chimne, "Comparative Effects of Enalapril and Amlodipine on the levels of Serum Angiotensin Converting Enzyme and Lipid Profile in Patients with Hypertension", International Journal of Biotechnology and Bioscience, 1(4), pp 444-450, 2011.

[16] G. Iyalomhe, E. Omogbai, A. Isah et al., " A Comparison of the Effects of Amlodipine and Hydrochlorothiazide Monotherapy on Lipid Metabolism in Hypertensive Nigerians with Type 2 Diabetes Mellitus", Journal of Diabetes \& Metabolism, 3 (10), pp 1-6, 2012.

[17] S. S. Pratibha, and C. K. Chitra "Effects of Calcium Channel Blockers on Different Biochemical Parameters in Essential Hypertensive Patients", National Journal of Basic Medical Sciences, 2(4), pp 353-356, 2012.

[18] S. V. Nedogoda, A. A. Ledyaeva, E. V. Chumachok et al., "Randomized Trial of Perindopril, Enalapril, Losartan and Telmisartan in Overweight or Obese Patients with Hypertension", Clinical Drug Investigation, 33(8), pp 1-9, 2013.

[19] I. Shaifali, A. K. Kapoor and H. K. Singh, "A Comparative Evaluation of Losartan/Hydrochlorothiazide (Fixed Combination) versus Amlodipine Monotherapy on Left Ventricular Hypertrophy, Biochemical Parameters and Adverse Effects in Patients of Hypertension”, Indian Journal of Clinical Practice, 24 (9), pp 823-829, 2014.

[20] M. Kaur, K. Kaur, GK. Bedi, GS. Sidhu and R. Sikand, "Effect of Felodipine on the Serum Lipid Profile of Patients with Hypertension", Indian Journal of Chemical Biochemistry, $15(2)$, pp 63-67, 2000 